\title{
DYNAMIC RESPONSE ANALYSIS OF DRILL PIPE CONSIDERING HORIZONTAL MOVEMENT OF PLATFORM DURING INSTALLATION OF SUBSEA PRODUCTION TREE
}

Fei Wang

Neng Chen

School of Mechatronic Engineering, Southwest Petroleum University, Chengdu, China

\begin{abstract}
In order to study the dynamic response of a drill pipe under the motion of the float platform, current and waves during the installation of a subsea production tree (SPT), a numerical model was established to analyse the mechanical properties of the drill pipe. The effects of the float platform motion on the mechanical behaviours of the drill pipe are carried out as well as the operation depth, submerged weight of the SPT, current velocity and drill pipe specification. At the same time, the evolution mechanism of the dynamic response of the drill pipe was also explored. The results show that the bending stress of the drill pipe approaches the maximum value when the platform moves to about one fourth of its period. Based on the research, the deeper the operation depth, the smaller the range of motion of the bottom of the drill pipe; the current velocity and the size of drill pipe have the greatest influence on the lateral displacement and bending stress.
\end{abstract}

Keywords: SPT installation, drill pipe, dynamic response, vibration range, bending stress.

\section{INTRODUCTION}

WBecause the installation of a subsea production tree (SPT) directly affects the success of deep water oil production and the economic efficiency of the whole project, an accurate grasp of the deformation and stress distribution where the SPT is attached at the bottom end has a positive effect on the ocean engineering. With the rapid development and utilisation of oil and gas resources from shallow sea to deep water, study of the dynamic response of the drill pipe underwater, which is related to the cost and risk of installing the SPT, has become a difficult and hot point in drill operation.

The literature offers many research studies on the drill pipe's dynamic response. Chakrabarti and Frampton [1] reported on the progress of riser analysis and gave a detailed derivation of the horizontal motion equation of the riser. Safai Hachemi [2] wrote a computer program based on theory and a numerical method to calculate the nonlinear dynamic response of deep water risers. Ahmad and Datta [3-4] used the time integration method and the frequency domain iteration method to analyse the effects of the relative velocity square drag term, drift oscillation, instantaneous ship motion and the velocity of the current on the bending stress of marine risers under random waves. Wang [5] introduced the dynamic equation of horizontal motion of the riser and put forward the finite element method to solve the displacement of the riser under the action of waves and current. Based on the study of Ahmad and Datta, Khan et al. [6] obtained the response time history of bending stress and the influence of various harmonics on the bending stress with ABAQUS/Aqua software when the SCR was subjected to random wave loads. Qi et al. [7] studied the structural force and strength check of the whole drilling riser, and at the same time carried out a weakness analysis and parameter sensitivity analysis of the drilling riser. Zhou et al. [8] discovered the "one third effect" of a deep water drilling riser under the condition of the shear flow through independent research and developed a mechanical property test system of a deep water drilling riser. Guo et al. [9] studied the dynamic response of the internal solitary wave, the surface wave and the platform motion and found that the internal 
solitary wave has a great influence on the displacement and stress of the drill pipe. Wang et al. [10] established a transverse vibration model during the installation of a riser by means of a variation method and minimum energy principle to analyse the influence of the harmonic motion of the platform on the transverse vibration of the riser. Fan et al. [11] analysed the influence of internal solitary waves on the mechanical properties of the riser in the process of expansion on the basis of solving the governing equation of the hang off mode of the drilling riser with Wilson's $\theta$ method and a generalised minimal residual method. Hu et al. [12] established a model varying the drill pipe length to analyse the dynamic effect of environmental loads on the stress and displacement and the model was solved by the Keller box method. Olszewski et al. [13] analysed the effect of the clamping force on the stress distribution of a riser with finite element software and verified it on a specially designed experimental platform. Wodtke et al. [14] analysed risers using the finite element method under the conditions of ocean load and connecting to different mining platforms to evaluate their operation conditions. Wang et al. [15] deduced the axial vibration differential equation by establishing a mechanical model of a pipe installation and analysed some factors that affect the natural frequency of axial vibration and the axial vibration load. Chen et al. [16] studied the influence of complex prestress on the natural frequency and modal shape of the riser's dynamic characteristics. Liu et al. [17] established a dynamic behaviour model of a riser system of a deep water drilling platform under the condition of emergency evacuation, which was solved by Newmark's method, and then its effectiveness was verified by ANSYS software.

Although there are many studies on the dynamic response of SPT installation, most of them are about different types of waves acting on the drill pipe, and there is little research on the impact of platform motion on the installation of the SPT. The purpose of this paper is to investigate the dynamic influence

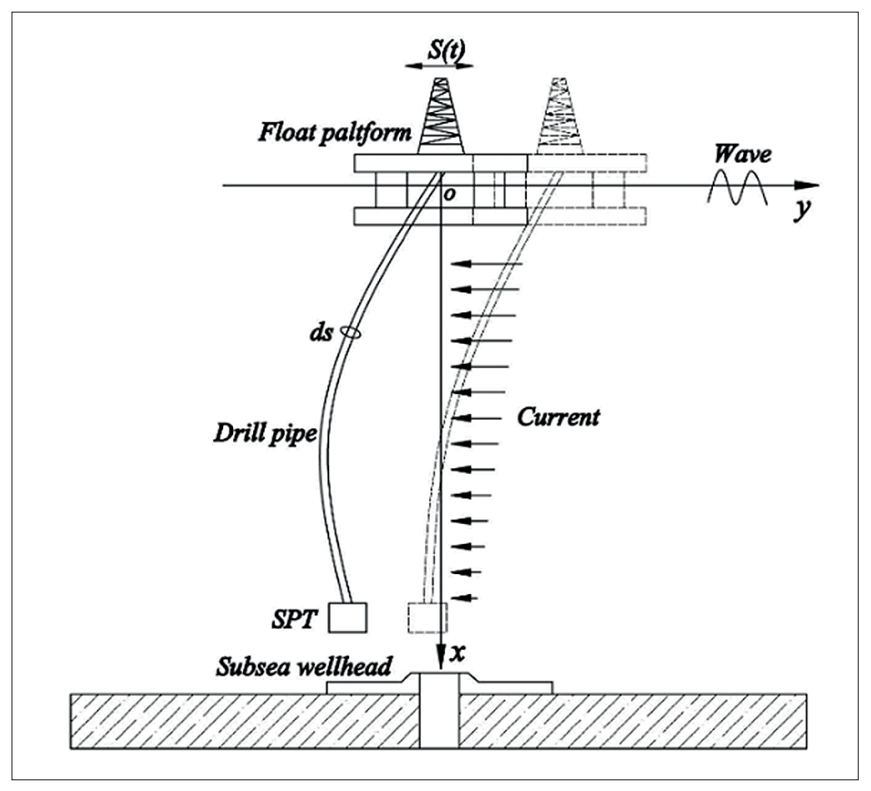

Fig. 1. Installation schematic diagram of SPT of the low frequency motion and the wave frequency motion of the platform on the drill pipe during the installation of the SPT. Based on the analysis of the axial and lateral loads of the drill pipe, mathematical models of the deformation and stress of the drill pipe under the action of waves, platform motion and current are established. The governing equation of the analysis model has been deduced and solved, and the parameters that may affect the dynamic response of the drill pipe have been considered. The research results can help personnel better understand the mechanical state of the drill pipe in the process of installing the SPT, and at the same time ensure the installation accuracy of the SPT and reduce the risk during installation.

\section{MECHANICAL MODEL}

\section{MODEL ANALYSIS}

Fig. 1 shows the schematic diagram of the installation by a drill pipe to lower the SPT. After the conductor is installed, the bottom end of the drill pipe with the SPT is lowered from the float platform to the bottom of the sea and connected to the subsea wellhead. In this process, the drill pipe is subjected to lateral current force, wave force, float platform movement and the axial gravity of the SPT. The global coordinate system is established with the SPT's downward point as the origin $O(0,0)$. The $x$ axis is perpendicular to the sea surface and the positive direction is directed to the subsea wellhead; the $y$ axis is parallel to the sea surface and the positive direction is in the opposite direction to the current.

It is assumed that the drill pipe experiences a small deformation under its own gravity and environmental load, and that the deformation only occurs in the xoy plane. A microelement segment of the drill pipe with length $d s$ is selected from Fig. 1 to analyse the dynamic response of the drill pipe during installation of the SPT. The force of

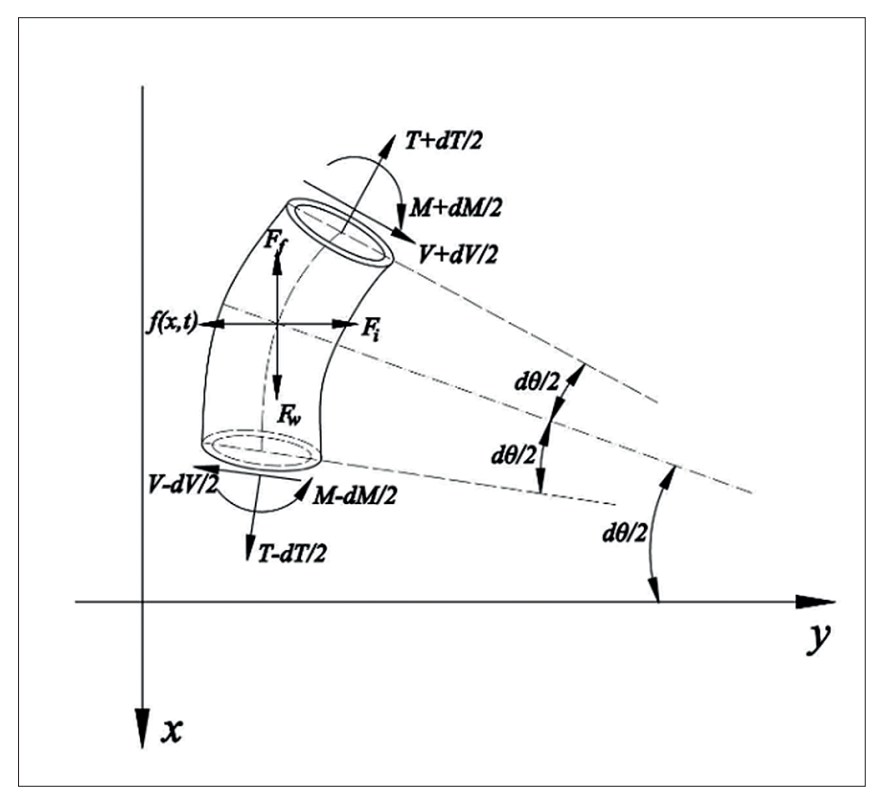

Fig. 2. Analysis model of drill pipe micro-element section 
the microelement segment is shown in Fig. 2, where $M, V, F W$, $F_{f}, F_{i}$, and $f(x, t)$ are the bending moment, shear force, gravity, buoyancy, inertia force and environmental force, respectively.

According to the force of the microelement segment, the equilibrium equations of the $x$ axis, $y$ axis and bending moment are as follows:

$$
\left\{\begin{array}{l}
\sum x=0:-\left(V-\frac{\mathrm{dV}}{2}\right) \sin \left(\theta-\frac{d \theta}{2}\right)+\left(V+\frac{\mathrm{dV}}{2}\right) \sin \left(\theta+\frac{d \theta}{2}\right) \\
+\left(T-\frac{\mathrm{dT}}{2}\right) \cos \left(\theta-\frac{d \theta}{2}\right)-\left(T+\frac{\mathrm{dT}}{2}\right) \cos \left(\theta+\frac{d \theta}{2}\right)+F_{W}-F_{f}=0 \\
\Sigma y=0:\left(V+\frac{\mathrm{dV}}{2}\right) \cos \left(\theta+\frac{d \theta}{2}\right)-\left(V-\frac{\mathrm{dV}}{2}\right) \cos \left(\theta-\frac{d \theta}{2}\right) \\
-\left(T-\frac{\mathrm{dT}}{2}\right) \sin \left(\theta-\frac{d \theta}{2}\right)+\left(T+\frac{\mathrm{dT}}{2}\right) \sin \left(\theta+\frac{d \theta}{2}\right)-f(x, t)+\text { mads }=0 \\
\Sigma M=0: d \mathrm{~T}\left(1-\cos \frac{d \theta}{2}\right)+\frac{1}{R_{\rho}} d M+2 V \sin \frac{d \theta}{2}=0
\end{array}\right.
$$

where $m$ is the unit length mass of the drill pipe, $\mathrm{kg}$; $a$ is the acceleration of the pipe in the negative direction of the $x$ axis, $\mathrm{m} / \mathrm{s}^{2} ; R_{\rho}$ is the radius of curvature of the microelement segment, $\mathrm{m}$.

The microelement section is considered a small amount, Hence, it can be obtained from Eq. (1) that $\cos d \theta=1$, $\sin d \theta=d \theta$. For the whole of the drill pipe, the transverse deformation of the drill pipe is small, so $d s=x, \cos \theta=1$, $\sin \theta=\theta=d y / d x, d \theta / d x=d^{2} y / d x$ can be obtained by the small deformation theory of the beam. The geometric relations obtained above are substituted into Eq. (1), and then simplified and sorted out. The governing equation of the drill pipe can be obtained by substituting the vertical balance equation and moment balance equation of the drill pipe into the horizontal balance equation:

$$
E I \frac{d^{4} y}{d x^{4}}-T(x) \frac{d^{2} y}{d x^{2}}+m \frac{d^{2} y}{d t^{2}}=f(x, t)
$$

where $E$ is the Young's modulus of the drill pipe, MPa; $I$ is the rotational inertia moment, $\mathrm{m}^{4} ; T(y)$ is the axial tension, $\mathrm{N}$; $m$ is the mass per unit length of drill pipe, $\mathrm{kg}$.

\section{BOUNDARY AND INITIAL CONDITIONS}

Because of the fixed connection with the float platform at the upper end of the drill pipe, the top of the drill pipe moves synchronously with the platform and the bending moment is related to the connection stiffness and the rotation angle. Hence, the upper boundary conditions are as follows:

$$
\left\{\begin{array}{l}
\left.y\right|_{x=0}=S(t) \\
\left.M\right|_{x=0}=\left.E I \frac{\partial y^{2}}{\partial x^{2}}\right|_{x=0}=\left.k_{b} \frac{\partial y}{\partial x}\right|_{x=0}
\end{array}\right.
$$

where $S(t)$ represents the lateral response of the platform motion; $k_{b}$ is the connection stiffness when $x=0, \mathrm{~N} / \mathrm{rad}$; $M$ is the bending moment, $\mathrm{MPa}$.

Because the bottom end of the drill pipe is free, there is no slope and shear force. Therefore, the lower boundary conditions are as follows:

$$
\left\{\begin{array}{l}
\left.\theta\right|_{x=N}=\left.\frac{\partial y}{\partial x}\right|_{z=N}=0 \\
\left.Q\right|_{x=N}=\left.\frac{\partial^{3} y}{\partial x^{3}}\right|_{z=N}=0
\end{array}\right.
$$

where $\theta$ is the angle of roll, $\operatorname{rad}$; $Q$ is the shear force, $\mathrm{N} ; N$ is the operation depth, $\mathrm{m}$.

Because the drill pipe has no displacement and velocity at the beginning, the initial conditions of the governing equation are as follows:

$$
\left\{\begin{array}{l}
\left.y\right|_{t=0}=0 \\
\left.y^{\prime}\right|_{t=0}=0
\end{array}\right.
$$

\section{LOAD DETERMINATION}

Because the SPT is connected directly to the bottom of the drill pipe, it can be simplified to a mass point. The axial tension is as follows:

$$
T(x)=G_{S P T}+0.25 \pi\left(\rho_{s}-\rho_{w}\right)\left(D_{o}^{2}-D_{i}^{2}\right)(N-x)
$$

where $x$ is the height of the node on the drill pipe to the sea surface, $\mathrm{m} ; G_{S P T}$ is the submerged weight of the SPT, N; $\rho_{s}$ is the density of the drill pipe, $\mathrm{kg} / \mathrm{m}^{3} ; \rho_{w}$ is the density of the sea water, $\mathrm{kg} / \mathrm{m}^{3}$; Do and $D_{i}$ are the outer diameter and inner diameter of the drill pipe respectively, $\mathrm{m}$.

The environmental load on the drill pipe is mainly caused by waves and currents. According to Morrison's equation [18], the environmental load can be expressed as follows:

$$
\begin{gathered}
f(x, t)=0.5 C_{D} \rho_{w} D_{o}\left[u_{w}(x)+u_{c}(x)\right]\left|u_{w}(x)+u_{c}(x)\right|+ \\
+0.25 \pi C_{M} \rho_{w} D_{o}^{2} \alpha_{w}(x) \\
\left\{\begin{array}{l}
u_{w}\left(x_{i}\right)=\frac{\pi H_{w}}{T_{w}} \exp \left(-k_{n} \cdot x_{i}\right) \cdot \cos \left(k_{n} y-\omega_{w} t\right) \\
a_{w}\left(x_{i}\right)=\frac{2 \pi^{2} H_{w}}{T_{w}^{2}} \exp \left(-k_{n} \cdot x_{i}\right) \cdot \sin \left(k_{n} y-\omega_{w} t\right)
\end{array}\right.
\end{gathered}
$$

where $\mathrm{C}_{D}$ is the drag force coefficient, a dimensionless quantity; $C_{M}$ is the inertia force coefficient, a dimensionless quantity; $u_{w}$ is the horizontal velocity of a water particle at the seawater depth $x, \mathrm{~m} / \mathrm{s} ; u_{c}$ is the velocity of the current at the sea surface, $\mathrm{m} / \mathrm{s} ; a_{w}$ is the acceleration of the water particle at water depth $x, \mathrm{~m} / \mathrm{s}^{2} ; H_{w}$ is the wave height, $\mathrm{m} ; T_{w}$ is the wave period, $\mathrm{s} ; k_{n}$ is the wave number; $\omega_{w}$ is the wave circular frequency.

In addition to the environmental load, the motion of the platform has a great effect on the mechanical behaviour of the drill pipe. From the study by Sexton and Agbezuge [19], the platform motion is as follows:

$$
\begin{gathered}
S(t)=S_{0}+S_{L} \sin \left(\frac{2 \pi t}{T_{L}}-\alpha_{L}\right)+ \\
+\sum_{i=1}^{N} S_{n} \cos \left(k_{n} S(t)-\omega_{n} t+\phi_{n}+\alpha_{n}\right)
\end{gathered}
$$


where $S_{0}$ is the mean offset, $\mathrm{m} ; S_{L}$ is the amplitude of the low frequency motion of the platform, $m ; T_{L}$ is the low frequency response period of the platform, $s ; \alpha_{L}$ is the phase angle between the wave and platform; $S_{n}$ is the amplitude response of the platform to the period and amplitude of the wave, $s ; k_{n}$ is the number of the wave; $\varphi_{n}$ is the wave phase angle; $\alpha_{n}$ is the phase angle between the platform motion and the wave of the period.

Because the platform motion caused by all the wave frequencies is too complicated, this paper only focuses on the low frequency motion of the platform and the surge response of the platform with a $180^{\circ}$ wave.

\section{MODEL SOLUTION}

The finite difference method is used to find the numerical solution of the definite solution of partial (or ordinary) differential equations and systems of equations. In this paper, the difference quotient is used instead of the derivative to discretise and solve the differential governing equation. In order to facilitate the calculation, one and three nodes are respectively added to the top and bottom of the drill pipe to carry out the auxiliary calculation. The solution region is divided into $M$ rows and $N+5$ columns, as shown in Fig. 3. $T$ represents the total time, $\Delta t$ is the time step, $N+5$ represents the total length of the drill pipe (including the virtual nodes), $h$ is the step length.

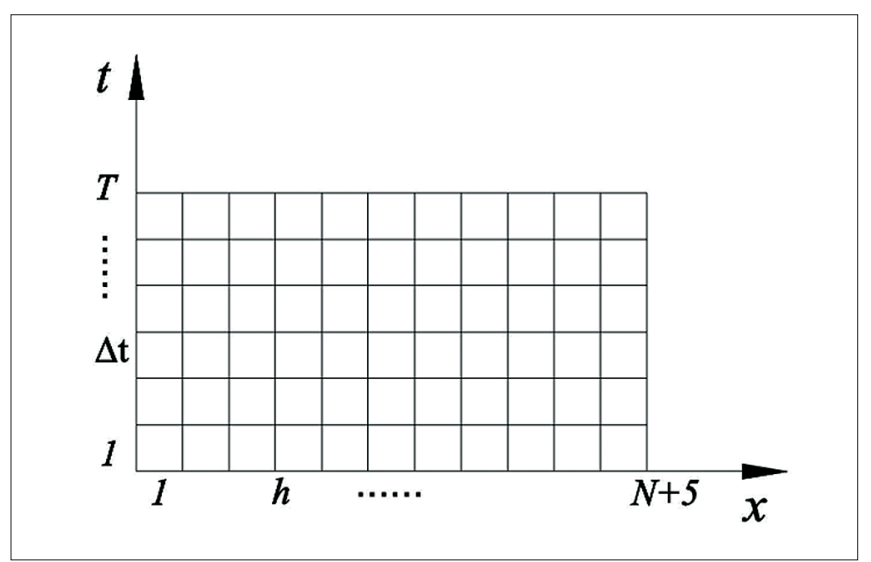

Fig. 3. Differential grid diagram

The finite difference method is used to discretise the governing differential equations (Eq. (2)) into:

$$
\begin{gathered}
E I \frac{y_{i 2-}^{m}-4 y_{i+1}^{m}+6 y_{i}^{m}-4 y_{i-1}^{m}+y_{i-2}^{m}}{h^{4}}-T(x) \frac{y_{i+1}^{m}-2 y_{i}^{m}+y_{i-1}^{m}}{h^{2}}+ \\
m \frac{y_{i}^{m+1}-2 y_{i}^{m}+y_{i}^{m-1}}{\Delta t^{4}}=f(x, t)
\end{gathered}
$$

The differential format of the drill pipe's top boundary condition, Eq. (3), is as follows:

$$
\left\{\begin{array}{l}
y_{2}^{m}=S_{2}^{m} \\
E I \frac{y_{3}^{m}-2 y_{2}+y_{1}^{m}}{h^{2}}=k_{b} \frac{y_{3}^{m} y_{1}^{m}}{2 h}
\end{array}\right.
$$

The differential format of the drill pipe's bottom boundary condition, Eq. (4), is as follows:

$$
\left\{\begin{array}{l}
\frac{y_{N+4}^{m}-y_{N+2}^{m}}{2 h}=0 \\
\frac{y_{N+5}^{m}-2 y_{N+1}^{m}+2 y_{N+2}^{m}-y_{N+1}^{m}}{h^{3}}=0
\end{array}\right.
$$

Sort out Eq. (9) to Eq. (11) as follows:

$$
\left\{\begin{array}{l}
y_{i}^{m+1}=a y_{i-2}^{m}+b y_{i-1}^{m}+c y_{i}^{m}+b y_{i+1}^{m}+a y_{i-2}^{m}+d-y_{i}^{m-1} \\
y_{2}^{m}=S_{2}^{m} \\
y_{1}^{m}=e y_{2}^{m}+f y_{3}^{m} \\
y_{N+4}^{m}=y_{N+2}^{m} \\
y_{N+5}^{m}=2 y_{N+4}^{m}-2 y_{N+2}^{m}+y_{N+1}^{m}
\end{array}\right.
$$

where

$$
\begin{aligned}
& a=\frac{E I \Delta t^{2}}{m h^{4}}, b=\frac{4 E I \Delta t^{2}}{m h^{4}}+\frac{T(x) \Delta t^{2}}{m h^{2}}, c=--\frac{6 E I \Delta t^{2}}{m h^{4}}-\frac{2 T(x) \Delta t^{2}}{m h^{2}}+2 \\
& d=\frac{\Delta t^{2} f(x, t)}{m}, e=\frac{4 E I}{2 E I+k_{b} h}, f=\frac{k_{b} h-2 E I}{k_{b} h+2 E I}
\end{aligned}
$$

The differential format of the initial condition is as follows:

$$
y_{i}^{1}=y_{i}^{2}=0
$$

By discretisation, the governing differential equations and boundary conditions are transformed into a series of linear equations, so that the higher order differential equations can be solved in a reduced order. The lateral displacement of each section of the drill pipe which changes with time can be obtained by solving Eq. (12), and other mechanical properties of the drill pipe can also be solved by the same method. The specific process of solving the lateral displacement of the drill pipe is shown in Fig. 4.

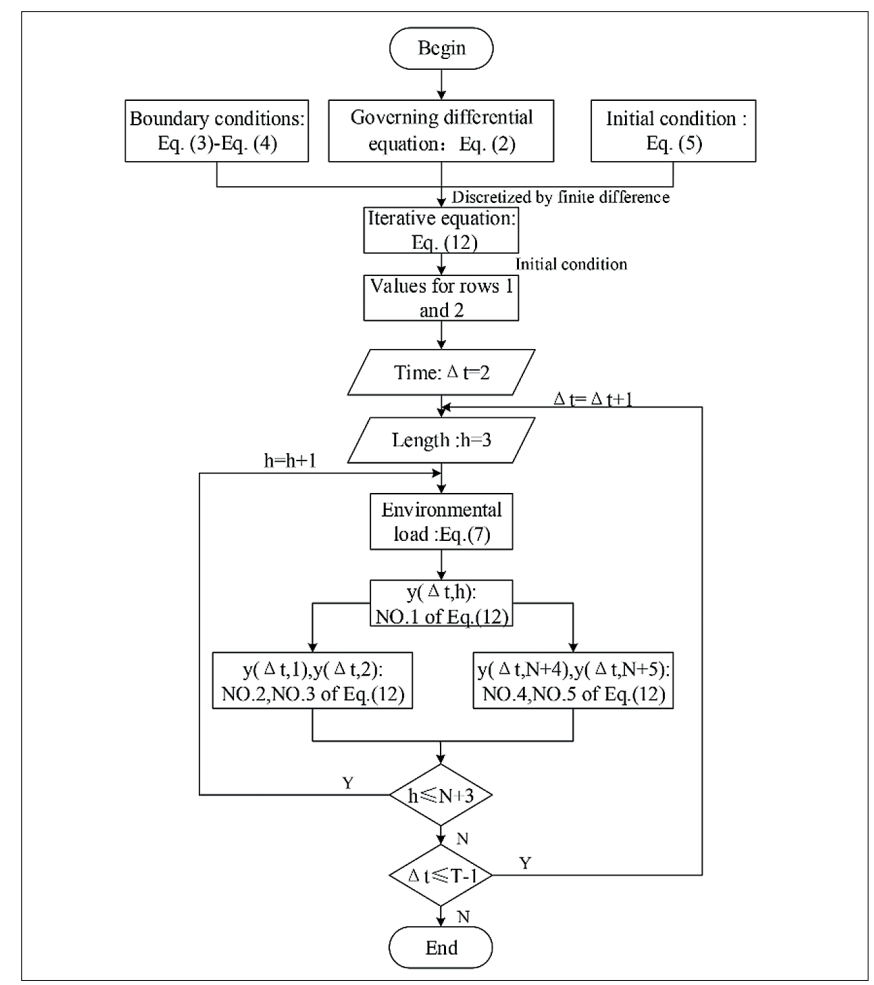

Fig. 4. Computational flow chart 


\section{EXAMPLE ANALYSIS}

A drilling operation in a certain sea area needs to install an SPT, where the operation parameters are as shown in Table 1.

Tab. 1. Operation parameters of SPT installation

\begin{tabular}{|c|c|c|c|}
\hline Parameters & Value & Parameters & Value \\
\hline $\begin{array}{l}\text { Operation water depth } \\
\qquad N(m)\end{array}$ & 600 & $\begin{array}{l}\text { Density of seawater } \rho_{w} \\
\left(\mathrm{~kg} \cdot \mathrm{m}^{-3}\right)\end{array}$ & 1030 \\
\hline Wave height $H_{w}(m)$ & 7 & Wave period $T_{w}(s)$ & 10 \\
\hline $\begin{array}{l}\text { Surface velocity of } \\
\text { current }(\mathrm{m} / \mathrm{s})\end{array}$ & 1.5 & $\begin{array}{l}\text { Drag force coefficient } \\
\qquad C_{D}\end{array}$ & 1 \\
\hline $\begin{array}{l}\text { Inertia force coefficient } \\
\qquad C_{M}\end{array}$ & 2 & $\begin{array}{l}\text { Outer diameter of the } \\
\text { pipe } D_{o}(\mathrm{~mm})\end{array}$ & 127 \\
\hline $\begin{array}{l}\text { Inner diameter of the } \\
\text { pipe } D_{i}(\mathrm{~mm})\end{array}$ & 101.6 & $\begin{array}{l}\text { Density of pipe } \rho_{s} \\
\left(\mathrm{~kg} \cdot \mathrm{m}^{-3}\right)\end{array}$ & 7850 \\
\hline $\begin{array}{l}\text { Young's modulus of the } \\
\text { pipe } E(\mathrm{GPa})\end{array}$ & 210 & $\begin{array}{c}\text { Submerged weight SPT } \\
\text { GSPT }(k N)\end{array}$ & 300 \\
\hline $\begin{array}{c}\text { Platform response period } \\
\text { TL (s) }\end{array}$ & 200 & $\begin{array}{l}\text { Platform response } \\
\text { amplitude } S_{L}(m)\end{array}$ & 8 \\
\hline $\begin{array}{l}\text { Connection stiffness } \mathrm{k}_{\mathrm{b}} \\
(\mathrm{N} / \mathrm{rad})\end{array}$ & 0 & & \\
\hline
\end{tabular}

In the process of calculation, the response of the platform is the composite motion of low frequency motion and the surge response of the platform, and its specific response is shown in Fig. 5. The maximum and minimum amplitudes of the platform response are $9.63 \mathrm{~m}$, and $-9.72 \mathrm{~m}$, respectively, and are not on the special time node.

Under the influence of horizontal force (generated by waves and current), axial force (generated by its own gravity and the gravity of the SPT) and platform motion, the maximum

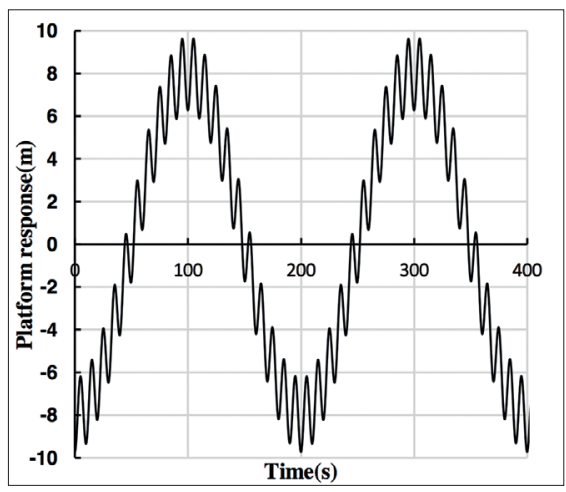

Fig. 5. Platform horizontal response motion

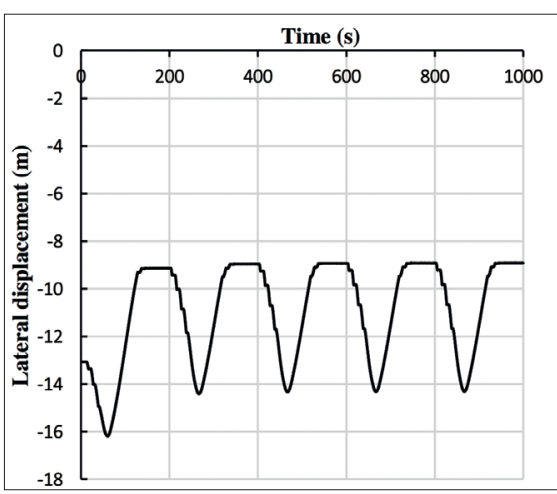

Fig. 7. History of movement of the bottom end of the drill pipe value and minimum value of lateral displacement of each node in the whole installation process are shown in Fig. 6.

It is worth noting that the maximum and minimum values (the absolute value of the extreme value and the following text is the same) in Fig. 6 are the vibration extremum of each node in the whole installation process, not the overall lateral displacement of the drill pipe at a certain time. It can be seen from Fig. 6 that, with the increase of operation depth, the extreme value of the drill pipe vibration increases gradually while the rate of increase decreases gradually. The extreme values of lateral displacement at the top end of the drill pipe are $-9.72 \mathrm{~m}$ and $9.63 \mathrm{~m}$, respectively, and the maximum and minimum lateral displacements at the bottom of the drill pipe are $-16.18 \mathrm{~m}$ and $-8.92 \mathrm{~m}$, respectively. During the whole installation process, the whole drill pipe vibrates within the range of the maximum and minimum values.

The historical movement of the lateral displacement of the bottom of the drill pipe is shown in Fig. 7. It can be seen that the extreme value of the lateral displacement in Fig. 6 includes the unstable vibration portion of the drill pipe due to the fact that the effect of the platform movement is not transmitted to the bottom of the drill pipe along the drill pipe in the early stages of the installation of the SPT. Hence, under the ideal conditions of this paper, the whole installation process is divided into two parts: one is the unstable period when the movement of the SPT has not yet been transferred to the bottom end; the other is the stable period when the movement is transmitted to the bottom end, and the bottom end of the drill pipe is subjected to regular motion. When the drill pipe is lowered and vibrated smoothly, the lateral vibration area is as shown in Fig. 8.

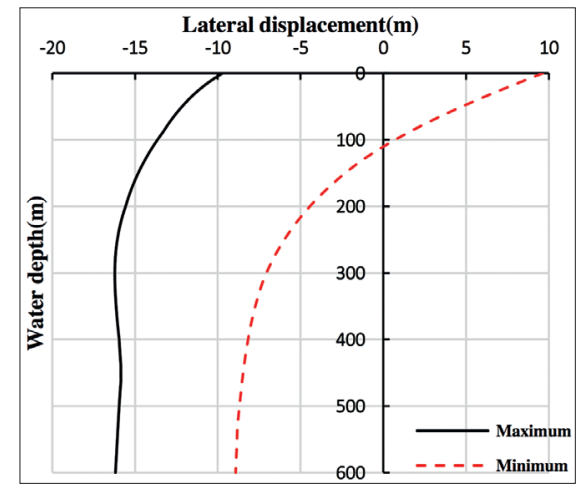

Fig. 6. Lateral displacement response of the drill pipe

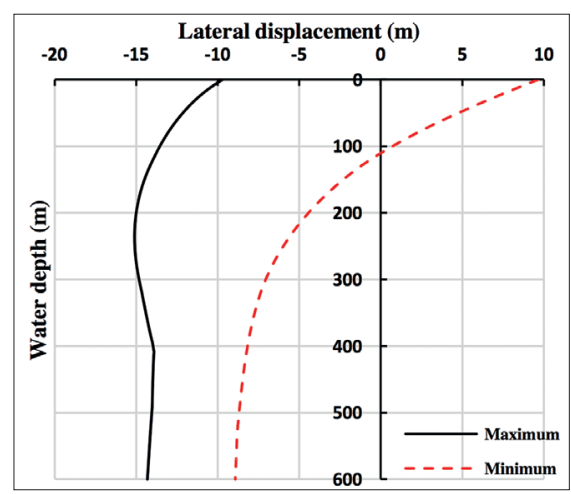

Fig. 8. Lateral displacement boundary of the drill pipe with stable vibration 
As can be seen from Fig. 7, when the response motion of the platform at the top end of the drill pipe is transferred to the bottom end, the bottom end of the drill pipe does not run according to the original trajectory at the top end of the drill pipe. The reason for this phenomenon is the attenuation caused by the resistance of the sea water, and the degree of attenuation is related to the operation depth. The intersection of the curve and the ordinate shows that the lateral displacement of the drill pipe under the current action is only $-13.06 \mathrm{~m}$, and then the bottom end of the drill pipe starts to experience distortion vibration when the stress wave is transmitted to the bottom due to the movement of the platform.

The trend in Fig. 8 is roughly similar to that in Fig. 6, but slightly different in value. The maximum and minimum values of the lateral displacement of the bottom end of the drill pipe in Fig. 8 are $-14.31 \mathrm{~m}$ and $-8.92 \mathrm{~m}$, respectively. The difference between the extreme value of the unstable stage and the extreme value of the stable stage is $25 \%$, so the lateral displacement of the bottom of the drill pipe in the unstable stage is also very important.

In order to more intuitively reflect the influence of the platform motion on the lateral displacement of the drill pipe during the stable period, the influence of the platform motion on the lateral displacement is measured by the standard deviation, and the standard deviation is shown in Fig. 9.

As can be seen from Fig. 9, the standard deviation is nearly linearly reduced in the first $500 \mathrm{~m}$; in other words, the influence of the platform motion on the lateral displacement decreases gradually with the increase of water depth. In the latter $100 \mathrm{~m}$, the standard deviation tends to increase, which may be caused by the inertia force of the SPT connected at the end of the drill pipe.

\section{EVOLUTIONARY MECHANISM OF DRILL PIPE DYNAMIC RESPONSE}

In the process of SPT installation, the distribution of the lateral displacement and bending stress of the drill pipe is particularly important for the success of SPT installation, so it is necessary to study these two parameters. In order to explore the influence of the platform motion on the process of these two parameters, five time nodes $\left(t=0, T_{L} / 4, T_{L} / 2,3 T_{L} / 4, T_{L}\right)$ of the platform response period are taken, and the dynamic influence of the platform movement on the lateral displacement and bending stress are shown in Fig. 10 and Fig. 11.

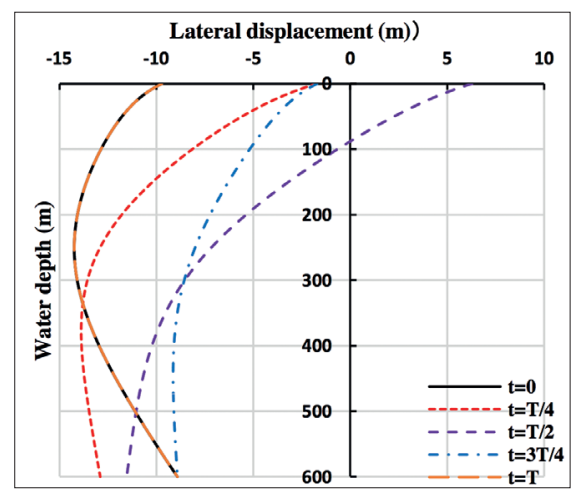

Fig. 10. Dynamic response of lateral displacement

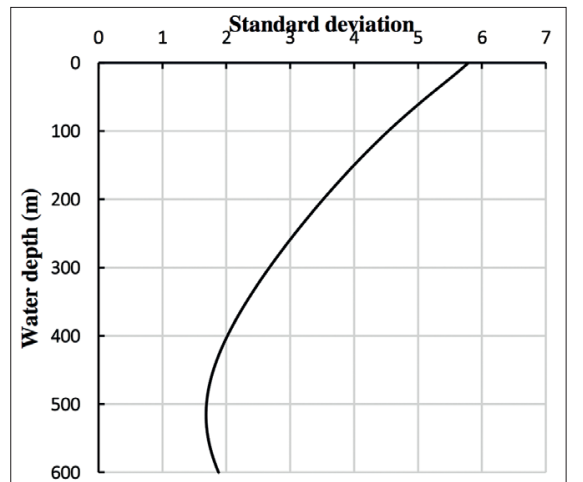

Fig. 9. Standard deviation of displacement during stability

It can be seen from Fig. 10 that when the upper end of the drill pipe reaches the extreme value, the lower end of the drill pipe does not reach the corresponding extreme value, but has a certain delay. When $t=T_{L} / 4$, there is a maximum lateral displacement of $12.9 \mathrm{~m}$ in each time node at the bottom end of the drill pipe; when $t=0,3 T_{L} / 4$, and $T_{L}$, there is a minimum displacement of $8.9 \mathrm{~m}$ in each time node at the bottom end of the drill pipe. This differs from the extreme value of the bottom of the drill pipe in Fig. 2 by $1.2 \%$ and $0.2 \%$, respectively. Because the motion state of the drill pipe is different at each time node, the lateral displacement of the drill pipe is not symmetrical.

Fig. 11 shows that the bending stress of the drill pipe reaches the maximum near the top, and then gradually decreases to zero with the increase of the operation depth (because there is only a large difference in the first few tens of metres, only the stress distribution of the first $50 \mathrm{~m}$ is shown, as is the same below). When $t=T_{L} / 4$, the maximum bending stress in each time node is $25.2 \mathrm{MPa}$; when $t=3 T_{L} / 4$, the minimum bending stress in each time node is $18.9 \mathrm{MPa}$. This corresponds exactly to the maximum and minimum lateral displacement at the bottom end of the drill pipe in Fig. 10. Therefore, the drill pipe is in the "dangerous" stage when $t=T_{L} / 4$.

\section{EFFECT OF OPERATION WATER DEPTH ON LATERAL DISPLACEMENT AND BENDING STRESS}

With the development of oil and gas exploitation to the deep sea, the depth of operation is the parameter that has to be considered. Five different ocean depths varying from $600 \mathrm{~m}$

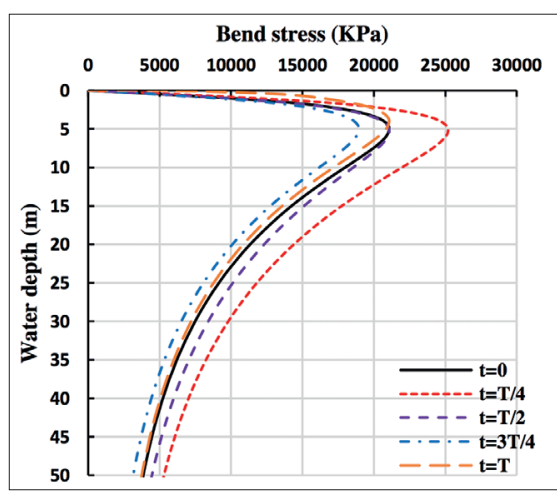

Fig. 11. Dynamic response of bending stress 
to $1400 \mathrm{~m}$ are selected to analyse the mechanical behaviour of the drill pipe, and the other working parameters are the same. The lateral displacement and bending stress of the drill pipe are shown in Fig. 12 and Fig. 13.

It can be seen from Fig. 12 that, with increase of the operation water depth, the maximum boundary and minimum boundary of the lateral displacement of the drill pipe are also gradually increased. The differences between the maximum value and the minimum value of the bottom end of the drill pipe in different water depths are $7.26 \mathrm{~m}, 6.9 \mathrm{~m}, 6.45 \mathrm{~m}, 5.12 \mathrm{~m}$ and $4.1 \mathrm{~m}$ respectively. If the platform rotates, the active range of the SPT is a circle whose diameter is the difference between the maximum and minimum lateral displacement at the bottom of the drill pipe. Hence, the deeper the water, the smaller the SPT range at the bottom of the drill pipe, and the higher the installation accuracy.

It can be seen from Fig. 13 that the bending stress increases rapidly to the maximum value in the first few metres, and then decreases gradually. The maximum bending stresses of different water depths are $30.8 \mathrm{MPa}, 27.9 \mathrm{MPa}, 25.6 \mathrm{MPa}$, 23.6 $\mathrm{MPa}$, and 21.9 MPa, respectively. Therefore, with increase of the operation depth, the bending stress decreases gradually, and the amplitude of the decrease is not large.

\section{EFFECT OF SUBMERGED WEIGHT OF THE SPT ON LATERAL DISPLACEMENT AND BENDING STRESS}

Since the submerged weight of most SPTs used under water ranges from $200 \mathrm{kN}$ to $400 \mathrm{kN}$, five data are selected to analyse its impact on the drill pipe, while the other operation parameters remain unchanged. The lateral displacement

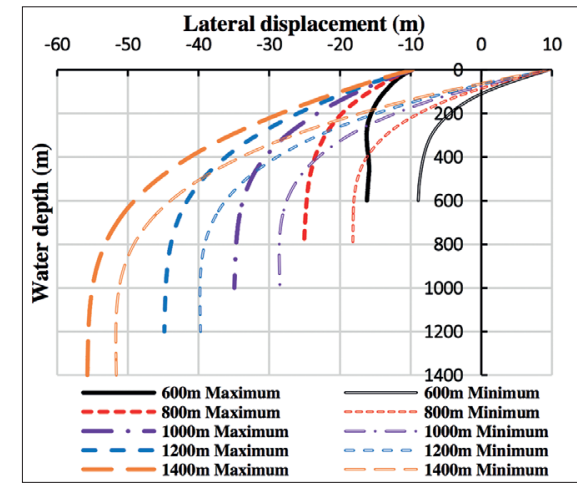

Fig. 12. Lateral displacement boundary with different operation depth

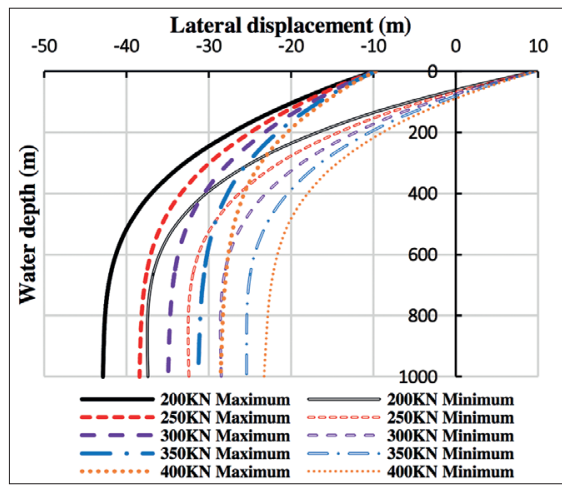

Fig. 14. Lateral displacement boundary with different submerge weight of SPT and bending stress of the drill pipe are shown in Fig. 14 and Fig. 15.

As can be seen from Fig. 14, with increase of the submerged weight of the SPT, the maximum boundary and minimum boundary of the lateral displacement of the drill pipe decrease gradually. The differences between the maximum and minimum lateral displacement of the bottom end of the drill pipe under the different submerged weights of the SPT are $5.46 \mathrm{~m}, 6 \mathrm{~m}$, $6.45 \mathrm{~m}, 5.88 \mathrm{~m}$ and $5.29 \mathrm{~m}$, respectively. It can be seen that, with increase of the submerged weight of the SPT, the vibration area of the drill pipe first increases and then decreases. Therefore, in order to ensure high installation accuracy, it is necessary to select the appropriate submerged weight of the SPT.

Fig. 15 shows that, with increase of the submerged weight of the SPT, the bending stress distribution curve of the drill pipe moves in the direction of a smaller value. The maximum bending stresses are $30 \mathrm{MPa}, 27.5 \mathrm{MPa}, 25.4 \mathrm{MPa}, 23.8 \mathrm{MPa}$ and $22.2 \mathrm{MPa}$, respectively. This phenomenon is caused by increase of the axial force and decrease of the lateral displacement.

\section{EFFECT OF CURRENT VELOCITY ON LATERAL DISPLACEMENT AND BENDING STRESS}

In order to explore the mechanical influence of the tidal current velocity of the sea surface on the drill pipe, five different current speeds ranging from $1.3 \mathrm{~m} / \mathrm{s}$ to $1.7 \mathrm{~m} / \mathrm{s}$ are selected for comparison, while the other working conditions remain the same. The distribution of the lateral displacement vibration boundary and maximum bending stress is shown in Fig. 16 and Fig. 17.

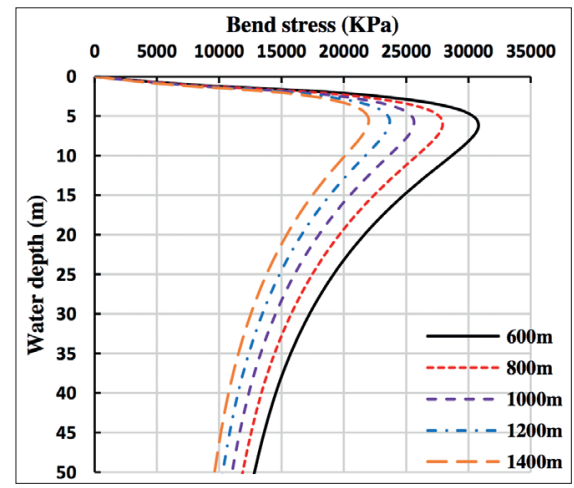

Fig. 13. Bending stress with different operation depth

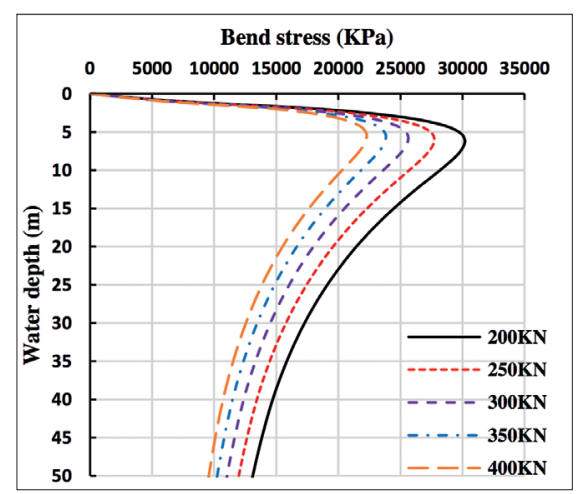

Fig. 15. Bending stress with different submerge weight of SPT 


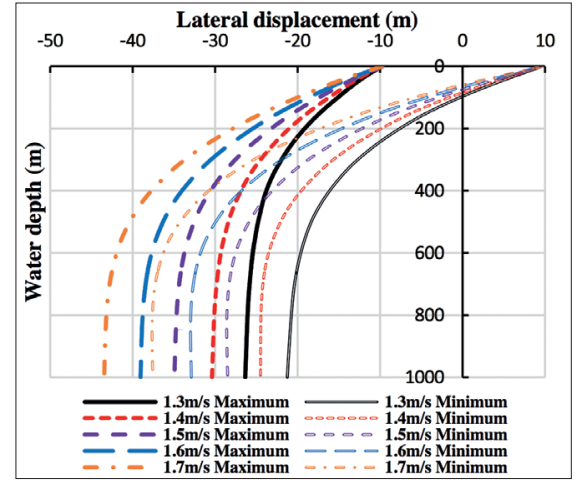

Fig. 16. Lateral displacement boundary with different current velocity

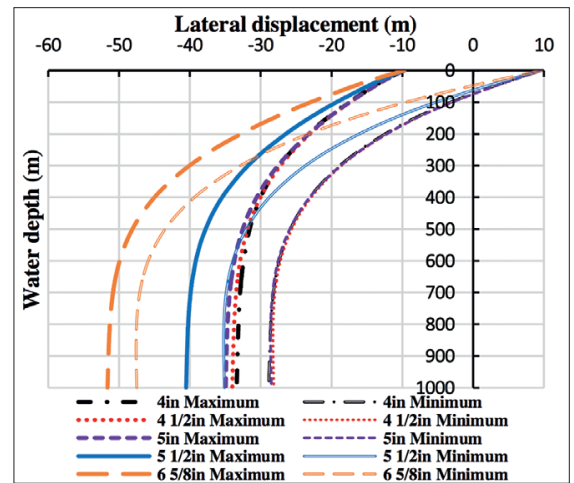

Fig. 18. Lateral displacement boundary with different drill pipe specifications

As shown in Fig. 16, the current velocity of the sea surface is only changed by $0.1 \mathrm{~m} / \mathrm{s}$, and the lateral vibration boundary of the drill pipe is very different. Under different current velocities, the ranges of activity at the bottom end of the drill pipe are $5.1 \mathrm{~m}, 5.87 \mathrm{~m}, 6.45 \mathrm{~m}, 6.17 \mathrm{~m}$ and $5.89 \mathrm{~m}$, respectively. It can be seen that the range of activity at the bottom of the drill pipe does not always increase as the velocity of the current increases. Therefore, in order to ensure accurate installation of the SPT, it is necessary to accurately measure and select the suitable sea surface current velocity.

It can be seen from Fig. 17 that the bending stress increases with increase of the current velocity; and the maximum bending stresses at different current velocities are 23.7 $\mathrm{MPa}$, 24.6 MPa, 25.6 MPa, 26.6 MPa and 27.58 MPa, respectively. The maximum bending stress increases by $1 \mathrm{MPa}$ for every $0.1 \mathrm{~m} / \mathrm{s}$ increase of the current velocity.

\section{EFFECT OF DRILL PIPE SPECIFICATION ON LATERAL DISPLACEMENT AND BENDING STRESS}

Five kinds of drill pipes of different specifications (ranging from 4 in to $65 / 8$ in) are used to analyse the dynamic influence, while the other operation parameters remain unchanged. The lateral displacement boundary and bending stress are shown in Fig. 18 and Fig. 19.

Fig. 18 clearly shows that when the drill pipe specification increases from 4 in to 5 in, the vibration boundaries of transverse displacement of the drill pipe change only slightly. However, when the drill pipe specification increases from 5 in to $65 / 8 \mathrm{in}$, the maximum and minimum values of the

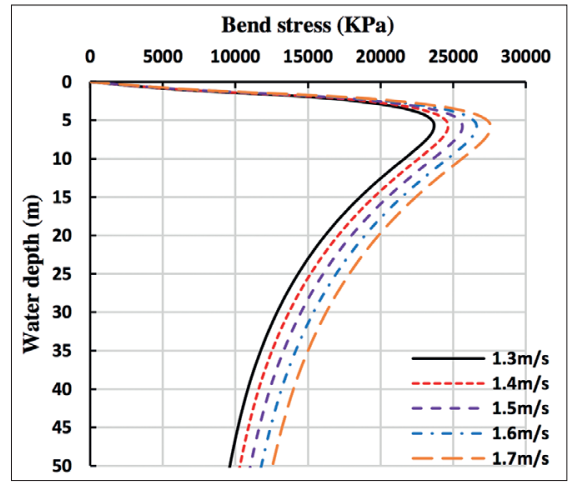

Fig. 17. Bending stress with different current velocity

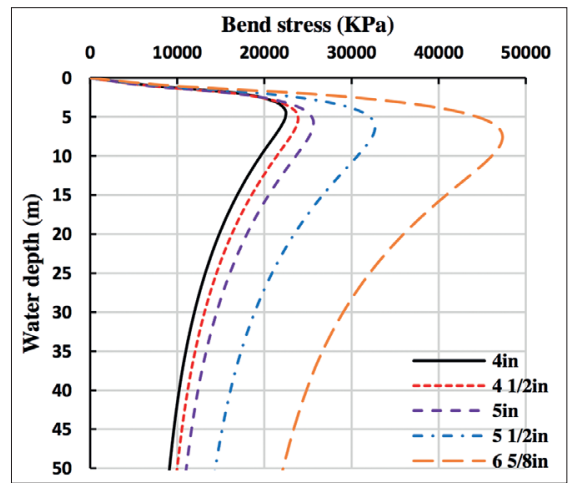

Fig. 19. Bending stress with different drill pipe specifications

lateral displacement of the drill pipe increase greatly. Although the extreme value of the lateral displacement increases with increase of the drill pipe specification, the range of movement of the lower end of the drill pipe first reduces and then increases.

It can be seen from Fig. 19 that the bending stress distribution curve moves to the right as the drill pipe specification increases. The maximum bending stress increases slightly from 4 in to 5 in, and in particular the maximum bending stress increases significantly from 5 in to $65 / 8$ in. The maximum bending stresses of the drill pipe with different specifications are 22.42 MPa, 23.85 MPa, 25.62 MPa, 32.66 MPa, and 47.27 MPa, respectively.

\section{CONCLUSION}

Based on the research reported above, the following conclusions and results can be obtained:

(1) The maximum displacement of the pipe at the bottom decreased by about $1.7 \mathrm{~m}$ when the variable environment load was considered.

(2) The bend stress of the pipe reaches its maximum value of $25.2 \mathrm{MPa}$ at $5 \mathrm{~m}$ and the displacement at bottom reaches its maximum value of $12.9 \mathrm{~m}$ when $t=T_{L} / 4$ ( $t$ reflects the variable time of the drill pipe, $T_{L}$ reflects the response period of the platform).

(3) The displacement of each joint of the pipe increases with the water depth, current velocity and specification of the pipe, and the distance between the SPT and the wellhead was approximately linear with the water depth. 
(4) The movement of the SPT increases with the specification of the pipe, weight of the SPT and current velocity at the first stage only, but then decreases gradually.

(5) The current velocity and the weight of the pipe significantly affect the bend stress of the pipe during the installation of the SPT and more attention should be paid to this during the design stage of the project.

\section{ACKNOWLEDGEMENT}

The authors would like to acknowledge the support of the Scientific Research Starting Project of SWPU (No.2017QHZ010), China.

\section{REFERENCES}

1. Chakrabarti S. K., Frampton R. E. (1982): Review of riser analysis techniques. Applied Ocean Research, 4(2), 73-90.

2. Safai Hachemi V. (1983): Nonlinear dynamic analysis of deep water risers. Applied Ocean Research, 5(4), 215-225.

3. Ahmad S., Datta T. K. (1989): Dynamic analysis response of marine risers. Engineering Structures, 11, 179-188.

4. Ahmad S., Datta T. K. (1992): Nonlinear response analysis of marine risers. Composite Structures, 43(2), 281-295.

5. Wang D. D. (2006): Computational analysis on loads and motion of underwater risers. Master's Thesis, Dalian University of Technology.

6. Khan R. A., et al. (2011): Nonlinear dynamic analysis of marine risers under random loads for deep water fields in Indian offshore. Procedia Engineering, 14, 1334-1342.

7. Qi B. (2012): Global strength analysis of ultra deepwater drilling riser. Master's Thesis, Harbin Engineering University.

8. Zhou S. W., Liu Q. Y., et al. (2013): The discovery of "One Third Effect" for deep water drilling riser: Based on the theoretical and experimental study of deformation characteristics of deep water drilling riser by ocean currents. China Offshore Oil and Gas, 25(06), 1-7.

9. Guo H. Y., Zhang L., et al. (2013): Dynamic responses of top tensioned riser under combined excitation of internal solitary wave, surface wave and vessel motion. Journal of Ocean University of China, 12(1), 6-12.

10. Wang Y. B., et al. (2015): Study on lateral nonlinear dynamic response of deepwater drilling riser with consideration of the vessel motions in its installation. Computers, Materials and Continua, 48(1), 57-75.
11. Fan H. H., et al. (2017): Dynamic analysis of a hang off drilling riser considering internal solitary wave and vessel motion. Journal of Natural Gas Science and Engineering, $37,512-522$.

12. Hu Y. L., et al. (2018): Dynamic behaviors of a marine riser with variable length during the installation of a subsea production tree. Journal of Marine Science and Technology (Japan), 23(2), 378-388.

13. Olszewski A., et al. (2018): FEM analysis and experimental tests of rigid riser hanging system. Polish Maritime Research, 25(2), 108-115.

14. Wodtke M., et al. (2018): FEM calculations in analysis of steel subsea water injection flowlines designing process. Polish Maritime Research, 25(3), 84-93.

15. Wang C., et al. (2019): Simulation of axial vibration characteristics of marine riser under suspension mode. Journal of System Simulation, 31(10), 2122-2130.

16. Chen L. Y., et al. (2019): Dynamic characteristic study of riser with complex pre-stress distribution. Polish Maritime Research, 26(3), 87-97.

17. Liu J., et al. (2018): Dynamic behavior of a deepwater hard suspension riser under emergency evacuation conditions. Ocean Engineering, 150, 138-151.

18. Wilson J. F. (Ed). (1991): Dynamics of offshore structures. Beijing Petroleum Industry Press.

19. Sexton R. M., Agbezuge L. K. (1976): Random wave and vessel motion effects on drilling riser dynamics. In 8th Annual Offshore Technology Conference.

\section{CONTACT WITH THE AUTHORS}

\author{
Fei Wang
}

e-mail:wangfei_swpu@126.com Southwest Petroleum University

Xindu, 610500 Chendu

China

\section{Neng Chen}

e-mail:2812087241@qq.com

Southwest Petroleum University

Xindu, 610500 Chendu

China 